ISSN 1676-3742

\title{
A visão de São Justino sobre a mulher: Personagens e Notícias
}

\author{
Saint Justin's notion about women: \\ People and Quotations
}

André Luiz Rodrigues da Silva

\begin{abstract}
Resumo
A nossa tentativa de aproximação e de entendimento sobre qual teria sido o papel da mulher em uma comunidade cristã primitiva específica é o objetivo central da presente pesquisa, na medida em que tal estudo se apoia em informações transmitidas nos escritos do apologeta cristão São Justino, filósofo e mártir, e propõe uma nova avaliação destas informações sob o ponto de vista da eclesiologia e da espiritualidade patrísticas, em diálogo com as fontes literárias da medicina e da anatomia nascente. Depois de considerar a perspectiva em que as fontes antigas e patrísticas permitem a análise do tema, articulam-se, por um lado, as informações transmitidas por São Justino com os textos do médico Galeno, para indicar como a medicina poderia oferecer noções compartilhadas pela religião, enquanto foca-se, por outro lado, nas metáforas femininas sobre a Igreja, onde possivelmente evoluíram os conceitos que apoiaram a reflexão sobre o papel da mulher na comunidade cristã.
\end{abstract}

Palavras-chaves: Apologetas. Igreja. Justino. Mulher.

\begin{abstract}
We try to establish an approach and to understand which would be the role of women in a specific, ancient Christian community as our main goal of this research, based on the pieces of information that saint Justin, philosopher
\end{abstract}


and martyr, provides in his apologetic books, so that we could use a process to analyze those issues from the point of view of the Patristic Ecclesiology and Spirituality, opening up the dialogue to literary source of medical treatises and the nascent anatomy. After considering the perspectives in which ancient and patristic sources would have allowed the analysis of the theme, we propose, on one hand, the connection between quotations transmitted by saint Justin and texts of the physician Galen, in order to show how both science and religion shared the same ideas, meanwhile, on the other hand, we would focus on the feminine allegories about the Church, where it would be like to help developing concepts that have permitted the reflection on the role of women in the Christian community.

Keywords: Apologists. Church. Justin. Women.

\section{Introdução}

Nosso principal objetivo nas seguintes páginas percorre, de uma forma bem concreta, o caminho proposto pelo Santo Padre, o papa Francisco, enquanto esse indicava aos estudiosos, em sua despedida do Brasil em virtude da Jornada Mundial da Juventude, a necessidade de compreender a falta de uma especificação mais teológica sobre a importância da mulher na comunidade cristã, reconhecendo ser "necessária uma profunda teologia da mulher".

Desta feita, a isso se conjuga a nossa proposta na tentativa de avançar sobre o assunto com o auxílio da reflexão que São Justino elaborou nos seus escritos, revelando uma combinação de temas que ainda não tinham sido valorizados por estudos precedentes. Em virtude desta combinação e da avaliação propostas por nós, estaremos chamando de "articulação" o nexo interpretativo dos elementos que representam os mais expressivos temas que envolvem a mulher na literatura justineia.

\section{Perspectiva de interpretação das fontes antigas}

A dificuldade de se aprofundar o tema sobre a mulher na antiguidade nasce das limitações que envolvem a finalidade das fontes antigas quando abordam este assunto. De modo geral, dos textos antigos de matizes jurídicas

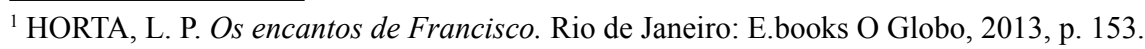


se percebe com menos constrangimento e maior objetividade aquilo que diz respeito ao desenvolvimento social da mulher em relação ao homem ou em relação à família, embora estime-se que seja uma tarefa árdua entendermos o comportamento comum da sociedade antiga nestes termos, já que as documentações legais que temos unanimemente contextualizam os leitores num ambiente processual e litigioso que, em geral, tendia a estabelecer os pareceres sobre doações, sucessões, divórcios e testamentos, sem que se preocupasse em descrever o dia a dia das pessoas e os detalhes do quotidiano em suas relações ${ }^{2}$. Para citarmos um exemplo deveras simples, especialistas identificam, na segunda metade do segundo século depois de Cristo, o ápice mais evoluído dos direitos romanos em favor da mulher, quando o assim chamado senatusconsultum Orfitianum decretou o direito que garantia aos filhos de uma mulher a sucessão intestada em preferência aos irmãos e parentes da mesma mulher ${ }^{3}$. Notamos que este é o período e o contexto em que Justino escreve os seus livros; por isso essas informações devem ser observadas com relevante atenção.

O cristianismo herda do judaísmo valores familiares complexos que exploram os mesmos temas segundo as ordens jurídicas e sociais instauradas pelos textos sagrados. No Deuteronômio, estabelece-se a lei do levirato ${ }^{4}$, segundo a qual, após a morte do marido, as viúvas deviam contrair núpcias com os seus cunhados. Morell salienta a antiguidade e a flexibilidade desta prática, citando os casos bíblicos importantes de Tamar e de Rute ${ }^{5}$. Já no tempo de Jesus, a querela sobre a ressurreição pincela um cenário onde os saduceus tentam confrontar a mesma questão do levirato, relatando a hipótese daquela mulher que hipoteticamente teria casado com sete irmãos, sem ter tido filhos com nenhum deles ${ }^{6}$. Dada a complexidade das relações, até mesmo os textos bíblicos se tornam apenas índice de uma realidade para a qual só em parte podemos nos lançar, tentando entendê-la.

${ }^{2}$ Cf. GOUREVITCH, D. - RAEPSAET-CHARLIER, M. T. La femme dans la Rome Antique. Paris: Hachette Litterature, 2001, p. 20. Para maiores detalhes sobre o tema conferir também EDMOND, L. La femme dans les sociétes antiques: actes des colloques de Strasbourg, mai 1980 et mars 1981. Strasbourg: AECR, 1983.

${ }^{3}$ Cf. EVANS, J. K. War, Women and Children in Ancient Rome. New York: Routledge Revivals, 1991, p. 13.

${ }^{4}$ Dt 25, 5-10.

${ }^{5}$ MORELL, O. R. "El levirato: del mundo bíblico al judaísmo clásico". Miscelánea de Estudios Árabes y Hebraicos, sección Hebreo 57 (2008), p. 223-228.

${ }^{6} \mathrm{Mt} 22,24-27$. 
O fato é que, além de garantir aos seus cidadãos facilidades e bem estar que não eram encontrados nas províncias, Roma tinha se tornado um ambiente privilegiado para as mulheres. Mesmo assim, a noção correta para compreendermos tal privilégio se distancia da tentativa de querer interpretar lugares, atividades, interferências, citações ou até mesmo na pesquisa cristã os ministérios eclesiásticos factualmente protagonizados pela figura feminina.

Há quem indique a necessidade de reconhecer a presença da figura masculina de cujo apoio a mulher dependia, sobretudo para que fosse garantida a manutenção daquele status que as mulheres casadas assumiam na sociedade. A despeito do fato de que até as fontes patrísticas tenham se tornado motivo de interesse crescente para a pesquisa com finalidades sociais e jurídicas que esclareçam a presença da mulher na antiguidade, em geral, todas as fontes antigas ainda continuam a indicar aspectos reduzidos, que não corresponderiam a todas as classes e circunstâncias sociais:

...por outro lado, a existência das mulheres dependia da posição social particular dos seus maridos e, portanto, pressupunha diferenças extremas. Além disso, quase que exclusivamente as fontes literárias antigas falam de mulheres de classe mais elevada assim como falam de figuras excêntricas, enquanto fórmulas estereotipadas, que raramente refletem a realidade e a individualidade, prevaleceram em relação às inscrições fúnebres sobre as mulheres de classes sociais intermediárias e mais baixas?

É oportuno que consideremos os limites das fontes antigas não como obstáculos para a pesquisa atual, mas como desafios que, superados, nos façam respeitar os valores mais autênticos, que sobreviveram a estruturas sociais tão rígidas e definidas.

Neste sentido, os escritos de São Justino ocupam um lugar privilegiado em relação a outras fontes. Em primeiro lugar, as suas obras se classificam como fontes interdisciplinares, enquanto oferecem dados inerentes ao paganismo, ao judaísmo e ao cristianismo antigos. Em segundo lugar, reafirma-se a importância do que foi dito acima, pela conjunção sócio-cultural-jurídica

${ }^{7}$ CHRIST, K. Die römische Keiserzeit: von Augustus bis Diokletian. München: Beck Wissen, 2006, p. 57: “... andererseits war die Existenz der Frauen von der jeweiligen gesellschaftlichen Stellung ihres Mannes abhängig und wies deshalb extreme Unterschiede auf. Schließlich kam hinzu, dass die literarischen antiken Quellen nahezu ausschließlich über Damen der Oberschicht sowie über exzentrische Gestalten berichten, wähend bei den Grabinschriften für die Frauen der mittleren und unteren Gesellschaftsschichten stereotype Formeln überwiegen, die nur selten Realität und Individualität widerspiegeln". 
que as informações dos seus textos apresentam, capacitando-nos a reconhecer em elementos precisos uma possível fusão intercultural que ali naqueles mesmos textos as mulheres representam. Enfim e em terceiro lugar, os livros de São Justino elucidam o relevante contexto que historicamente documentou a importância da mulher para a antiguidade, seja pelo período em que estes livros foram escritos, seja pela origem romana do autor.

\section{Primeira Articulação: Medicina e Religião.}

Após alguns anos de questionamento que tentasse elucidar o significado de alguns tétricos pormenores dos escritos de São Justino, lucra-nos agora que esta proposta para a presente articulação sobre as personagens e as notícias inerentes à descrição que ele faz sobre a mulher deva partir do contexto que a medicina da sua época ilustrava. Ao afirmar que a origem de todos os homens seja produzida pela necessidade de um germe úmido ( $\dot{\xi} \xi$ v $\gamma \rho \hat{\alpha} \varsigma$

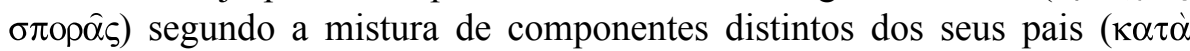

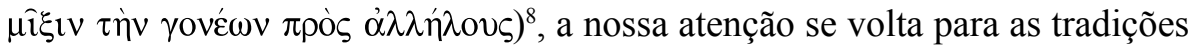
judeu-cristãs que se cruzam com as informações que "tecnicamente" a medicina tentava indicar sobre aquilo que acreditava-se ser a fecundação de uma pessoa. É incrível como já possa existir um parecer cristão sobre a fecundação ao lado de uma proposta médica, sem que esses tenham inevitavelmente que se contradizer. De fato, o germe húmido pertence amplamente à linguagem hermenêutica em cujos limites, segundo Nautin, se fixou a visão bíblica da criação entre vários autores patrísticos dos primeiros séculos, tal qual pode ser intuído em fragmentos da obra de Orígenes ou nos escritos posteriores de Numênio de Apaméia e de Porfírio9.

Ora, desde o tempo de Hipócrates de Cós (380 a.C.), a literatura médica já tinha se preocupado em responder às questões a respeito da fecundação humana, traçando pela fisiologia, como também pelas leis próprias que emergem da diferença entre os corpos dos homens e das mulheres e, enfim, pelo calor natural emitido através dos corpos, os pressupostos da mistura de que provavelmente São Justino está falando ${ }^{10}$.

${ }^{8}$ I Apol. 61, 10.

${ }^{9}$ Cf. NAUTIN, P. “Genèse 1, 1-2, de Justin à Origène”. Études Augustiniennes 38 (1973), pp. 61-94; CAQUOT, A. "Brèves remarques exégétiques sur Genèse 1, 1-2". In: VIGANAUX, P. In principio. Paris: Institut d'Études Augustiniennes, 1973, pp. 9-21.

${ }^{10} \mathrm{Cf}$. GUTTMACHER, A. F. Hippocrates on intercorse and pregnancy: an English translation of On Semen [De genitura] and On the development of the child [De natura foetus]. Nova York: Ed. H. Schuman, 1952, pp. 31-46. 
Pensava-se, então, que após a relação sexual ambos, homem e mulher, oferecessem uma quantidade de sêmen que, ao se misturar, resultasse na vida concebida. Asseverando que o sêmen masculino (óppevos $\sigma \pi \hat{\eta} p \mu \alpha$ ) se distin-

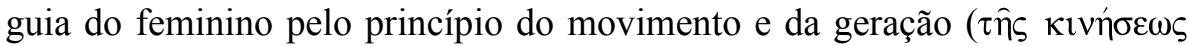

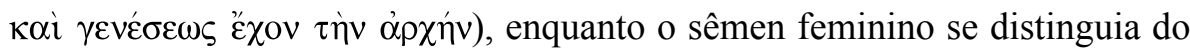

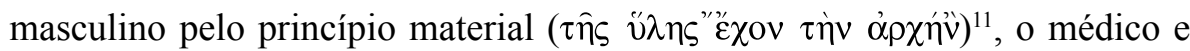
filósofo romano Galeno se espelhava na doutrina aristotélica para justificar o processo da fecundação a partir de suas sessões de dissecação animal, que lhe renderam o título de pai da anatomia. Pela técnica da dissecação de animais, Galeno teria desenvolvido as intuições dos médicos gregos Herófilo e Erasistrato, que favoreciam a possibilidade de associar inteiração às diversas funções dos órgãos humanos de forma que tais funções dependessem umas das outras, acreditando, por exemplo, que tanto os nervos quanto os pensamentos surgissem do coração humano ${ }^{12}$.

Ainda sobre o processo de fecundação, acreditava-se que, se o homem e a mulher produzissem sêmens fortes, isso explicaria porquê o sexo do seu bebê era de um menino. Se os dois oferecessem sêmens fracos, uma menina haveria de nascer. Enfim, o gênero da criança também poderia ser determinado por aquele que oferecesse o sêmen mais forte, caso um deles não fosse capaz de produzir o sêmen forte ${ }^{13}$. Não resta dúvida sobre o fato que os antigos se questionassem sobre o assunto e de que, a seu modo, buscassem razões plausíveis para a explicação do fato.

Não há motivos suficientemente claros que levem alguém a acreditar que São Justino tenha alguma razão para desenvolver as minúcias da doutrina médica que lhe precedera, mas se torna curiosa a forma com que ele repetidamente fala do sangue de Cristo como partícipe de uma ordem miraculosa em que o sangue não proceda de sêmen humano:

E fala-se também do 'sangue da uva', para dar a entender que aquele que havia de aparecer teria certamente sangue, mas não sangue de sêmen

\footnotetext{
${ }^{11}$ Sobre o sêmen 516, 5. Cf. DE LACY, P. On Semen / Galen. CMG 5, 3, 1. Berlim: Akademie Verlag, 1992, p. 68

${ }^{12}$ YOUNT, L. The Father of Anatomy. Galen and his dissections. Nova York: Enslow Publishers, 2010, p. 19: "Galen learned about two phiysicians who had lived in Alexandria during that time. Their names were Herophilus and Erasistratus. Most of what was known about the inside of human body had come from their work".

${ }^{13}$ Da natureza do homem, 6. Cf. LONIE, I. M. On the nature of the child. Corpus Hyppocraticum. Nova York: de Gruyter, 1981, p. 131.
} 
humano e sim da virtude divina. $O$ verbo é a primeira virtude ou potência depois de Deus, pai e soberano de todas as coisas, e filho seu. Como esse se tornou carne e nasceu homem, nós diremos mais adiante ${ }^{14}$.

Quando a Escritura diz 'o sangue da uva', ela quer significar figurativamente que Cristo tem de fato sangue, porém não por sua descendência humana, e sim pela força de Deus. Porque do mesmo modo em que o sangue da uva não foi gerado pelo homem, mas por Deus, da mesma forma a Escritura indicou antecipadamente que o sangue de Cristo não viria da descendência humana, mas da força de Deus. Portanto, senhores, essa profecia que vos citei demonstra que Cristo não é homem nascido de homem, segundo a maneira comum dos homens ${ }^{15}$.

A maneira comum, pois, de conceber o nascimento do homem como vindo do homem segundo o aparecimento do sangue do sêmen humano é fator determinante para acreditarmos que São Justino estivesse pensando no processo de fecundação segundo a análise da medicina antiga. Segundo a teoria que Galeno herdara de Hipócrates, o sangue humano nasceria do sêmen humano ${ }^{16}$. O simples fato de São Justino ser favorável à associação das funções de um composto e outro já indica uma grande aproximação dos interesses da medicina antiga. Após tornar-se consciente de tal processo, maiores seriam as razões para

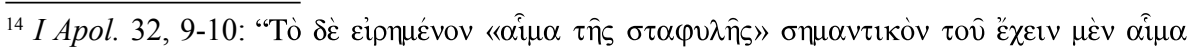

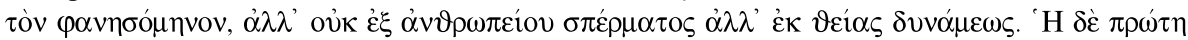

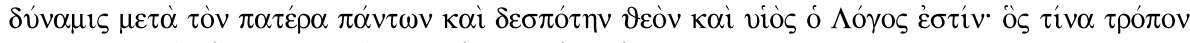

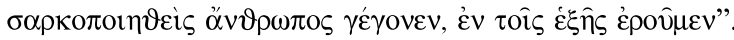

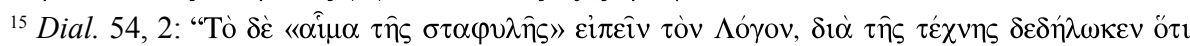

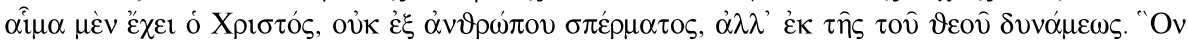

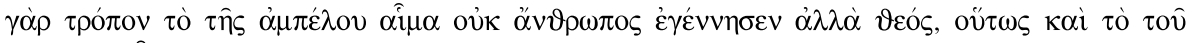

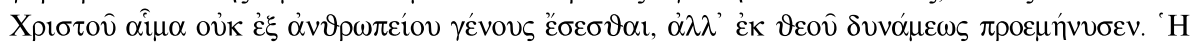

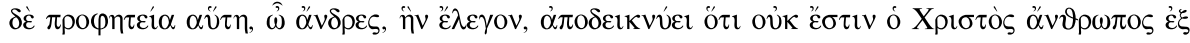

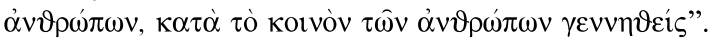

${ }^{16}$ Cf. BRAIN, P. Galen on bloodletting: a study of the origins, development, and validity of his opinions. Cambridge: Cambridge University Press, 1986, p. 5: "Galen attributes final causes to nature because, in his view, she is also an intelligent and purposive agent. She does everething with an aim in mind, and arranges everything in the best possible way; as both Aristotle and Galen repeatedly say, she does nothing in vain. The purposive nature operates in bodies through certain faculties or power (dynameis, dynamis) which she has, on which Galen wrote a special work. Her principal activities are genesis, growth and nutrition. Genesis is concerned with the formation of the embryo. Operating through the semen, which has the alternative faculty, she changes the mestrual blood of the mother, which is retine in the body during pregnancy, into the tissues and organs of the new animal". 
São Justino insistir que o sangue de Cristo, porém, jamais poderia proceder do

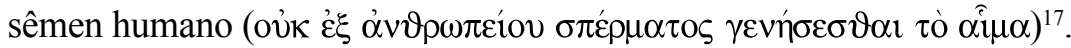

Dentro do discurso que a medicina fazia, há espaço para lembrar que São Justino cita Is 64, 6 em certa alusão à menstruação ${ }^{18}$, mas sem explanar o seu ponto de vista sobre esse assunto. De fato, a abordagem bíblica deste tema numa perspectiva de interdependência entre as vestes da mulher menstruada e o valor ético que isso sugeriria constitui o núcleo fundamental e mais antigo da interpretação deste texto. Estudiosos indicam que a função do texto é a criação de uma relação entre o tema da menstruação e a impureza para evidenciar a confissão dos pecados para a qual o povo de Deus deveria ser levado ${ }^{19}$. Outra implicância indireta pode aparecer na exemplificação que o filósofo mártir traz para os seus leitores na primeira Apologia:

Façamos uma suposição. Se não fôsseis o que sois e de quem sois e alguém vos mostrasse o sêmen humano e uma imagem pintada de um homem, afirmando que esta se forma daquele, por acaso acreditaríeis antes de vê-lo nascido? Ninguém se atreveria a contradizer isso ${ }^{20}$.

Mais uma vez, parece que aqui os dois princípios estejam se conjugando: "não ser o que é" pode coincidir tanto com o "germe úmido" que relatamos anteriormente, como o "não ser de quem é" se aproxima também do significado da "mistura dos componentes biológicos dos pais". Em consequência, é oportuno intuir que, de uma maneira ou de outra, a visão justineia sobre a mulher parta de um parecer médico compartilhado com a tradição cristã. Só neste sentido, por exemplo, poderíamos decifrar a argumentação sobre a impossibilidade da mulher ser circuncidada, segundo o ponto de vista de uma reflexão fisiológica propriamente paralela em relação à defesa apresentada por São Justino. Ou seja, São Justino está convencido de que a circuncisão não seja necessária, sendo ele mesmo incircunciso $(\dot{\alpha} \pi \varepsilon p i ́ \tau \mu \eta \tau \sigma)^{21}$. Desta maneira, enquanto procura uma

\footnotetext{
${ }^{17}$ I Apol. 32, 11.

${ }^{18}$ Cf. Dial. 25, 4.

${ }^{19}$ PHILIP, T. S. Menstruation and Childbirth in the Bible. Fertility and Impurity. Studies in Biblical Literature 88. New York: Peter Lang Publishing, 2006.

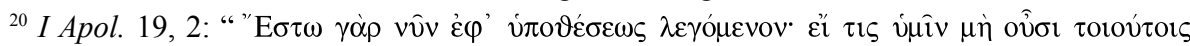

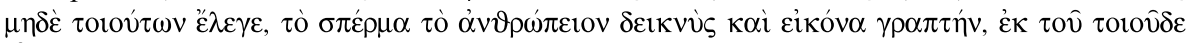

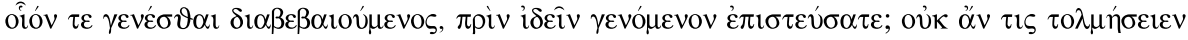

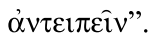

${ }^{21}$ Dial. 28, 2.
} 
prova para a irrelevância da circuncisão para si, que é homem, no fato de trazer

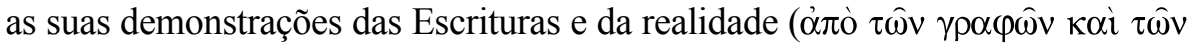
$\pi \rho \alpha \gamma \mu \alpha \dot{\tau} \tau \omega v)^{22}$, admite que para as mulheres essa irrelevância seja fisiológica:

O fato de que o sexo feminino não possa receber a circuncisão da carne prova que essa circuncisão foi dada como sinal e não como obra de justificação. No que diz respeito a todo o tipo de justiça e virtude, Deus quis que as mulheres tivessem a mesma capacidade que os homens para adquiri-las; em troca, vemos que a configuração da carne é diferente no homem e na mulher ${ }^{23}$.

Salientamos que, no período final da vida de São Justino a medicina se destacara com Galeno adentrando o cenário imperial romano, onde o médico filósofo reuniria em suas sessões de dissecação algumas mulheres da nobreza romana $^{24}$. Outrossim, a notícia de mulheres interessadas em seguir seus mestres e deles aprender o discurso filosófico que autenticasse o seu ensinamento aparecera tanto em Galeno quanto em Justino, supondo, como fazem os críticos, o elevado grau de participação ativa de Caritón $^{25}$, aquela mulher que fora surpreendida na escola de Justino e que, pelo fato de estar associada à escola do filósofo cristão, junto ao seu mestre e aos demais companheiros, tinha sido martirizada, depois de afirmar com toda coragem "ser cristã pelo

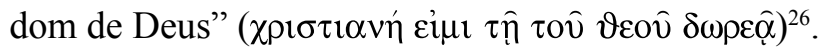

Em nível literário-patrístico, a mulher ocupa um lugar de relevante destaque na obra de São Justino, ao contrário do que os pesquisadores geralmente conseguem indicar quando tratam do mesmo assunto a partir dos demais autores da antiguidade ${ }^{27}$. Evitando generalizar este modo de

${ }^{22} I d$. Mais uma vez aqui elucida-se a presença dos dois princípios que tínhamos comentado antes.

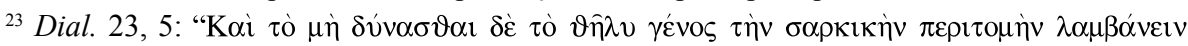

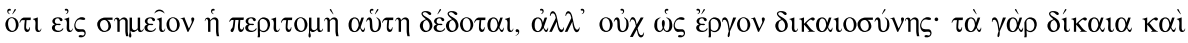

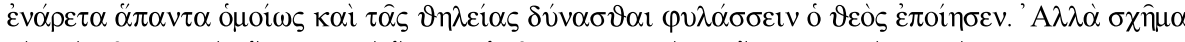

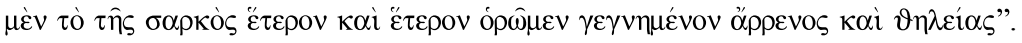

${ }^{24}$ Cf. POTTER, D. S. Life, death, and entertainment in the Roman Empire. Michigan: University of Michigan Press, 1999, p. 63.

${ }^{25}$ Act. Mart. Iust. I, 1.

${ }^{26}$ Act. Mart. Iust. IV, 2.

${ }^{27}$ Cf. KIEFEL, K. Frauen im frühen Christentum - zwischen Anerkennung und Unterdrückung. Berlim: Epubli, 2012. Kiefel se torna porta voz da mulher em defesa da sua figura cristã que foi construída num cenário literário concentrado em homens como autores e, em contra partida, numa sociedade em cujas relações a mulher se via e era marginalizada. 
analisar o papel que a mulher ocupava na comunidade cristã antiga, não seria oportuno apoiar leituras tendenciosas do início da I Apologia, onde São Justino menciona nominalmente o seu pai, Prisco, e seu avô, Báquio ${ }^{28}$, como se isso pudesse indicar ideias de desprezo ou desigualdade social ${ }^{29} \mathrm{em}$ relação às mulheres da sua família ou às mulheres em geral, dado que São Justino, além de inúmeras vezes citar mulheres como exemplo naquilo que faziam, em outras partes da sua obra também faz menções dignas à sua mãe, todavia ${ }^{30}$. De fato, é impossível que ele esteja pensando ou apenas na figura paterna ou tão pouco apenas na figura materna quando conclui que todos os homens tenham medo de uma paternidade pobre, sofrida e desonrosa ( $\left.\pi \varepsilon v i \alpha \varsigma \grave{\eta} \pi \alpha \dot{\vartheta} \eta \eta \hat{\eta} \dot{\alpha} \delta o \xi i \alpha \varsigma \pi \alpha \tau \rho \imath \chi \alpha \varsigma_{\varsigma}\right)^{31}$. Certamente, esta referência deveria ser entendida no contexto dos diversos exemplos de homens e de mulheres virtuosos apresentados por São Justino.

\section{Segunda Articulação: Espiritualidade Eclesial e Perfeição Cristã.}

A outra articulação que nós gostaríamos de propor se estabelece entre a espiritualidade eclesiástica e a consequente inovação do valor ético da perfeição humana. Nada deve ter trazido maior benefício para a interpretação do papel da mulher na comunidade cristã do que a alusão bíblica da Igreja como mulher e esposa ${ }^{32}$. Lidamos com um grupo de citações bíblicas pertinentes à mulher que está em desenvolvimento no que diz respeito ao seu valor para a espiritualidade eclesial.

$\mathrm{Na}$ comunidade romana isso se destaca, como no caso da obra do Pastor de Hermas, onde o semblante mutante da anciã-jovem é tão forte em relação à

\footnotetext{
${ }^{28}$ I Apol. 1, 1.

${ }^{29}$ São interessantes os resultados auferidos pelo estudo da Professora Jennifer Kunst da Universidade de Boston sobre o sexo e a violência nos textos de Justino. No entanto, como em outras leituras inadequadas de autores modernos, a professora trai - segundo o nosso jeito de entender - o que mais valioso pertença à obra de Justino, ou seja, a vontade de equiparar homem e mulher tanto no plano da natureza, quanto sobretudo no aspecto do respeito mútuo sem distinção. Kunst aborda os homens como se Justino quisesse interpretá-los através do sinal de força, enquanto as mulheres são o oposto, simbolizando a fraqueza. Cf. KUNST, J. "Enslaved to demons: sex, violence and the Apologies of Justin Martyr". In Penner, T. - Stichele, C. V. Mapping gender in ancient religious discourses. Leiden: Brill, 2007, p. 455.

${ }^{30}$ I Apol. 61, 5.

${ }^{31}$ I Apol. 12, 8.

${ }^{32}$ Cf. Ef. 5, 23; Ap. 12, 1-6; Ap. 21, 2-5;
} 
natureza da igreja ${ }^{33}$ quanto, em relação ao apelo ético, serão representadas as doze virgens desta obra ${ }^{34}$. Isso prova que a comunidade romana antiga apoiava a articulação deste processo a partir de uma interpretação arrojada e benéfica para o futuro da compreensão da mulher no seio da Igreja.

Retornamos aos escritos de São Justino onde verificamos os mesmos elementos, devendo reconhecê-los como componentes inerentes ao ensinamento da comunidade romana ao longo dos primeiros séculos. Aliás, uma expressão concreta da espiritualidade eclesial é verificada no final do Diálogo com Trifão, onde Lia e Raquel se tornam modelos do povo hebreu e

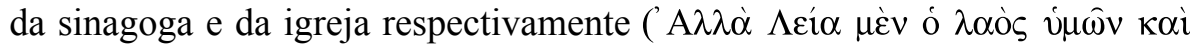

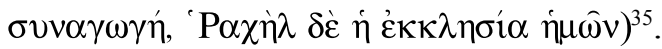

Como Jacó serviu às suas duas esposas, também Cristo serve aos dois povos $^{36}$. Perceba-se que Lia constituía um princípio bivalente correspondente ao valor natural que - intuímos - possa existir em Raquel: literalmente Lia era o modelo do povo hebreu e do lugar onde o povo hebreu se reunia, ou seja, a sinagoga. Pensar que Raquel se identifique apenas como o lugar onde os cristãos se reuniam (casas, templos etc.) é limitar o valor que o próprio texto confere. Por isso, deve-se aceitar que Raquel seja um modelo concreto para a aplicação bivalente do conceito "igreja", onde se reforça tanto o valor espiritual quanto a individualização desta categoria nas realidades locais concretas, o que para nós hoje seriam as paróquias.

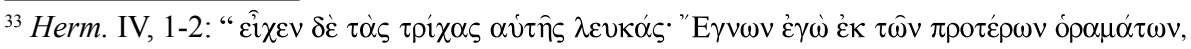

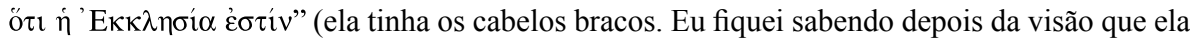
era a Igreja).

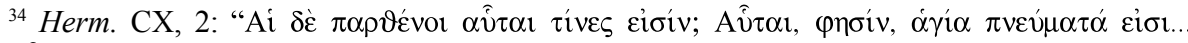

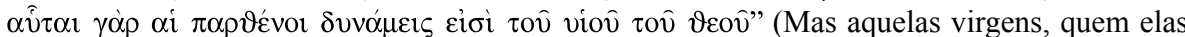
são? Respondeu: estas são espíritos santos... essas virgens são as potências do filho de Deus).

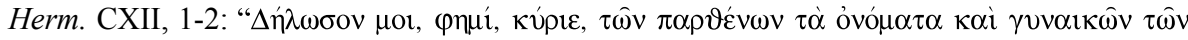

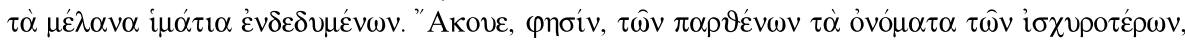

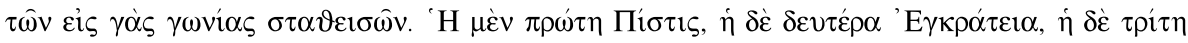

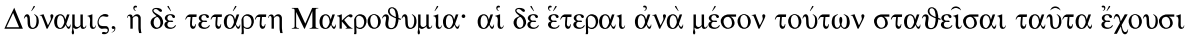

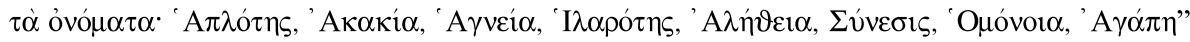
(Diga-me, senhor, - eu disse - o nome das virgens e das mulheres vestidas de preto. Escuta, disse, o nome das virgens mais fortes, as mesmas que estam nos ângulos: A primeira é a fé, a segunda è temperança, a terceira è a potência, a quarta é a paciência. As outras, que se encontram entre as primeiras, têm por nome simplicidade, inocência, santidade, alegria, verdade, inteligência, concórdia, caridade).

${ }^{35}$ Dial. 134, 3.

${ }^{36}$ Idem.
} 
Por falta de entendimento sobre o que estava diante dos nossos olhos, uma leitura meticulosa dos textos de São Justino nos fez parar por vários meses sobre uma afirmação do Diálogo com Trifão, onde o filósofo cristão reafirmava o valor da monogamia, tentando dizer que isso poderia ser explicado pelo fato dos cristãos se sentarem debaixo de uma parreira. Na verdade, as traduções que nós conhecíamos sugeriam isso ${ }^{37}$. No entanto, nós jamais entendemos de verdade como o "sentar-se debaixo da parreira" poderia se tornar uma prova em favor da monogamia. Por isso e porque não encontramos qualquer outra associação entre a monogamia e a parreira na literatura patrística, decidimos propor pessoalmente uma tradução, que trouxesse à luz essa característica da mística eclesiástica:

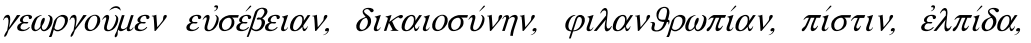

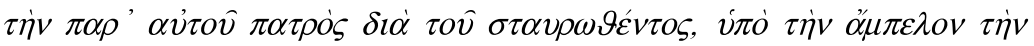

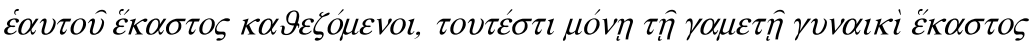

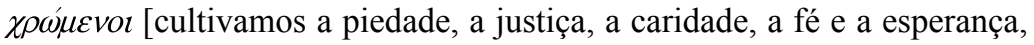
que nos vêm do seu Pai por meio do crucificado. Cada um de nós se senta debaixo da sua parreira \{sc. da parreira do Pai\}, isto é, cada um tem considerado a si mesmo única esposa \{do crucificado\} $]^{38}$.

A principal mudança da nossa tradução em relação às demais reside

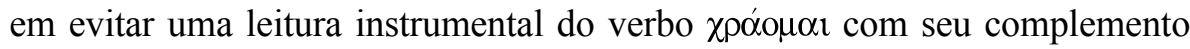
em dativo para designar "utilização" ou "serviço", quando percebemos que o significado desta construção também possa insinuar "tratamento" e "consideração", o que se reforça pela omissão natural do dativo reflexivo

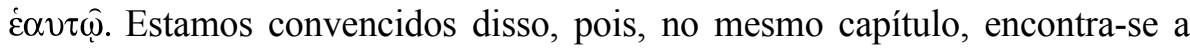
afirmação de que a vinha plantada por Deus e por Cristo salvador seja o seu

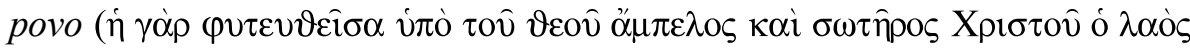

${ }^{37}$ Dial. 110, 3: "Cada um de nós senta-se debaixo da sua parreira, isto è, cada um usa apenas de sua legítima mulher". Cf. STORNIOLO, I. - BALANCIN, E. M. Justino de Roma, I e II Apologias; Diálogo com Trifão. São Paulo: Paulus, 2005, p. 278. “...chacun étant assis dessous sa propre vigne, je veux dire jouissant de son unique et légitime femme". Cf. BOBICHON, PH. Justin Martyr, Dialogue avec Tryphon. Édition critique, traduction, commentaire. Paradosis 47/1. Friburgo: Academic Press Fribourg, 2003, p. 479. “...each of us sitting under his vine, that is, each one living with only his own wife". Cf. FALLS, T. B. St. Justin Martyr, Dialogue with Trypho. Michigan: The Catholic University of America Press, 2003, p. 165. "Stiamo seduti ciascuno sotto la propria vite, cioè abbiamo rapporti solo con la legitima consorte". Cf. VISONÀ, G. Giustino, Dialogo con Trifone. Milano: Paoline, 1988, p. 320.

${ }^{38}$ Dial. 110, 3. Tradução nossa. 
$\alpha \hat{v} \tau o \hat{v} \dot{\varepsilon} \sigma \tau \imath)^{39}$. Mais adiante um pouco e sempre dentro do mesmo contexto, o texto fala sobre o risco que os cristãos corriam de perder as suas próprias

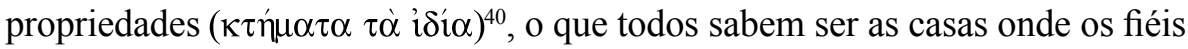
celebravam a fé cristã. Assim, nós aceitaríamos mais a alusão da vinha como referência à participação eclesiástica do que propô-la como reforço para defesa da monogamia.

Em função do apelo ético, São Justino recorre a um clássico texto de Xenofonte, onde transmite o encontro de Héracles com duas mulheres:

Xenofonte conta que, ao chegar em uma bifurcação, vieram ao encontro de Héracles a virtude e a maldade, na forma de mulheres. A maldade estava vestida com roupas finas, tinha rosto atraente e adornado com enfeites, e disse a Héracles que, se ele a seguisse, ela o faria viver sempre no prazer e enfeitado com o mais belo ornamento, semelhante ao que ela usava. Ao contrário, a virtude, com rosto e vestes severos, lhe disse: 'se seguires a mim, não te enfeitarei com beleza ou adorno passageiro e corruptível, mas com enfeites eternos e belos ${ }^{41}$.

Nós nos perguntamos sobre qual consequência a abertura para estes dois níveis de metáfora envolvendo a mulher possa resultar e assumimos o risco de dizer que a participação da mulher na possibilidade de chegar à perfeição humana - valor tipicamente inaugurado por São Justino - seja a melhor resposta. Se nós estivermos certos, isto significa que o valor da perfeição humana que se alarga a todas as pessoas está derivando da importância com as quais as metáforas femininas foram observadas pela comunidade cristã em perspectiva eclesiástica e aqui talvez encontremos um dos maiores efeitos da

\footnotetext{
${ }^{39}$ Dial. $110,4$.

${ }^{40}$ Dial. $110,5$.

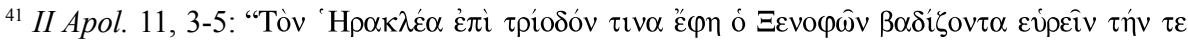

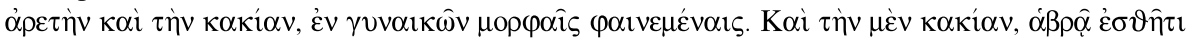

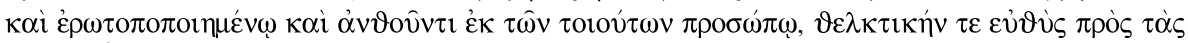

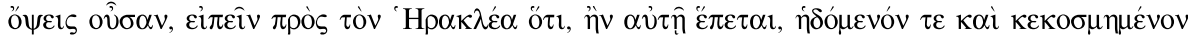

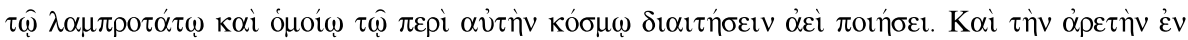

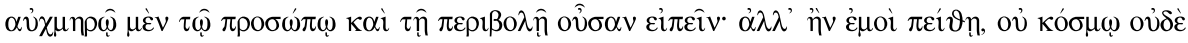

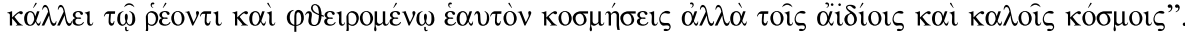
A importância de Xenofonte na obra de São Justino é respaldada pelo empréstimo que o mártir romano faz do outro autor quando usa tecnicamente o termo $\alpha$ $\pi$ o $\mu v \eta \mu o v \varepsilon v ́ \mu \alpha \tau \alpha$ para designar os Evangelhos como memórias dos apóstolos. Cf. OSBORN, E. F. Justin Martyr. Tübingen: Mohr Siebeck, 1973, pp. 123-124.
} 
presença da mulher na antiguidade. A quem interessar possa, relembramos que nós escrevemos um artigo nos Cadernos Patrísticos, onde mostramos como São Justino superou o modelo helênico de perfeição, ao considerar a possibilidade de todos serem perfeitos, independente do sexo ou da condição social ${ }^{42}$. Hoje retomamos o assunto, pensando exclusivamente na concepção cristã sobre a mulher como referência que não permitiu aos antigos engessarem de maneira redutiva a questão da mesma forma como os filósofos faziam.

\section{Considerações em destaque}

Os quatro conceitos que apresentamos nesta pesquisa (a. a participação da mulher na fecundação segundo o cristianismo da época; b. a participação da mulher na fecundação segundo a medicina da época; c. a espiritualidade eclesiástica com base nas metáforas femininas; $d$. a possibilidade para mulher de alcançar a perfeição humana) são temas que, ao mesmo tempo em que auxiliam a interpretação do vasto conteúdo do ensinamento de São Justino sobre a mulher, também permitem aos novos estudos que se afastem de tendências emancipatórias ou releituras políticas não apropriadas para este tema.

Oxalá possamos tratar futuramente de temas como a virgindade de Maria em relação aos mitos gregos ${ }^{43}$, a quebra de preconceitos em vista das ações nobres dos "marginalizados" mulher ${ }^{45}$, o apelo ético diante da mulher ${ }^{46}$, entre outros temas, sob a perspectiva daquilo que destacamos neste artigo.

\section{Conclusão}

A partir dos exemplos e das referências femininas apresentadas por São Justino é possível reconstruir um caminho mais adequado para compreendermos a função da mulher na antiguidade e o seu papel na comunidade cristã. Entre a religião e a medicina aparece um novo conceito que nos permite aproximar de uma mulher valorizada, cujas características

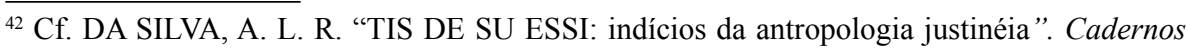
Patrísticos 6 (2008), p. 35-43.

${ }^{43}$ I Apol. 22, 5; 32, 7; 44, 3; 46, 5; 54; Dial. 34, 8; 65, 1; 71, 3.

${ }^{44}$ I Apol. 4, 1; 18, 2; II Apol. 1, 2.

${ }^{45}$ I Apol. 5,2; 21, 5; 27, 1-2 (com relação aos recém-nascidos); II Apol. 4 (5), 3; Dial. 13, 8; 42 , 3.

${ }^{46}$ I Apol. 15, 1; 64, 5. 
fisiológicas não lhe condicionavam a se tornar objeto de preconceito ou de juízos que a subjugassem. Entre a espiritualidade eclesiástica e o chamado à perfeição pode-se responder com objetividade sobre o papel que a mulher desempenhara na história da teologia, percebendo isso da grande importância que as metáforas femininas tiveram no processo de compreensão do cristianismo dos primeiros séculos. A observação que se faz procura ultrapassar os textos normalmente citados, percebendo a riqueza de detalhes sobre as personagens e as notícias sobre a mulher que ainda inspiram os estudiosos a se debruçarem na pesquisa para o melhor entendimento dos autores patrísticos.

\section{Referências Bibliográficas}

BOBICHON, PH. Justin Martyr, Dialogue avec Tryphon. Édition critique, traduction, commentaire. Paradosis 47/1. Friburgo: Academic Press Fribourg, 2003.

BRAIN, P. Galen on bloodletting: a study of the origins, development, and validity of his opinions. Cambridge: Cambridge University Press, 1986.

BUENO, D. R. Actas de los mártires, texto bilingüe. Madrid: BAC, 1963.

CAQUOT, A. "Brèves remarques exégétiques sur Genèse 1, 1-2". In: VIGANAUX, P. In principio. Paris: Institut d'Études Augustiniennes, 1973, pp. 9-21.

CHRIST, K. Die römische Keiserzeit: von Augustus bis Diokletian. München: Beck Wissen, 2006.

DA SILVA, A. L. R. "TIS DE SU ESSI: indícios da antropologia justinéia”. Cadernos Patrísticos 6 (2008), p. 35-43.

DE LACY, P. On Semen / Galen. CMG 5, 3, 1. Berlim: Akademie Verlag, 1992.

EDMOND, L. La femme dans les sociétes antiques: actes des colloques de Strasbourg, mai 1980 et mars 1981. Strasbourg: AECR, 1983.

EVANS, J. K. War, Women and Children in Ancient Rome. New York: Routledge Revivals, 1991.

FALLS, T. B. St. Justin Martyr, Dialogue with Trypho. Michigan: The Catholic University of America Press, 2003. 
GOUREVITCH, D. - RAEPSAET-CHARLIER, M. T. La femme dans la Rome Antique. Paris: Hachette Litterature, 2001.

GUTTMACHER, A. F. Hippocrates on intercorse and pregnancy: an English translation of On Semen [De genitura] and On the development of the child [De natura foetus]. Nova York: Ed. H. Schuman, 1952.

HORTA, L. P. Os encantos de Francisco. Rio de Janeiro: E.books O Globo, 2013.

JOLY, R. Hermas, le Pasteur, introduction, texte critique, traduction et notes. Paris: Sources Chrétiennes, 1997.

KIEFEL, K. Frauen im frühen Christentum - zwischen Anerkennung und Unterdrückung. Berlim: Epubli, 2012.

KUNST, J. "Enslaved to demons: sex, violence and the Apologies of Justin Martyr". In PENNER, T. - STICHELE, C. V. Mapping gender in ancient religious discourses. Leiden: Brill, 2007.

LONIE, I. M. On the nature of the child. Corpus Hyppocraticum. Nova York: de Gruyter, 1981.

MORELL, O. R. "El levirato: del mundo bíblico al judaísmo clásico". Miscelánea de Estudios Árabes y Hebraicos, sección Hebreo 57 (2008), p. 213-245.

NAUTIN, P. "Genèse 1, 1-2, de Justin à Origène". Études Augustiniennes 38 (1973), pp. 61-94.

OSBORN, E. F. Justin Martyr. Tübingen: Mohr Siebeck, 1973.

PHILIP, T. S. Menstruation and Childbirth in the Bible. Fertility and Impurity. Studies in Biblical Literature 88. New York: Peter Lang Publishing, 2006.

POTTER, D. S. Life, death, and entertainment in the Roman Empire. Michigan: University of Michigan Press, 1999.

STORNIOLO, I.- BALANCIN, E. M. Justino de Roma, I e II Apologias; Diálogo com Trifão. São Paulo: Paulus, 2005.

VISONÀ, G. Giustino, Dialogo con Trifone. Milano: Paoline, 1988.

YOUNT, L. The Father of Anatomy. Galen and his dissections. Nova York: Enslow Publishers, 2010. 
André Luiz Rodrigues da Silva

Doutor em Teologia e Ciências Patrísticas pelo Instituto Patrístico

gostiniano - Roma

Professor de Patrologia e Metodologia Teológica

Instituto Superior de Teologia da Arquidiocese do Rio de Janeiro

Rio de Janeiro / RJ - Brasil

e-mail: leleur@yahoo.it

Recebido em: 11/06/15

Aprovado em: 06/09/15 